\title{
Hereditary angioedema: New therapeutic options for a potentially deadly disorder
}

\author{
Frank J Eidelman
}

\begin{abstract}
Although the biochemistry of hereditary angioedema (HAE) is fairly well understood today, the lag in diagnosis of a decade or more suggests that clinicians have low awareness of this disease. This lag in diagnosis and hence treatment certainly stems from the rarity and complexity of the presentation which can be easily mistaken for allergic and nonallergic reactions alike. The symptoms of the disease include acute swelling of any or multiple parts of the body. The attacks may be frequent or rare, and they may vary substantially in severity, causing stomach discomfort or periorbital swelling in mild cases and hypovolemic shock due to abdominal fluid shift or asphyxiation in the most severe cases. Given that these patients are at significant risk for poor quality of life and death, greater awareness of this disease is needed to ensure that newly available, effective medications are used in these patients. These new medications represent significant advances in HAE therapy because they are targeted at the plasma cascades implicated in the pathophysiology of this disease. The clinical presentation of $\mathrm{HAE}$, overlapping symptoms with other angioedemas, and available therapies are reviewed.
\end{abstract}

\section{Introduction}

In 1888, Sir William Osler provided a medical description of angioedema (AE) that distinguished an inherited form of the disease[1]. His description was the first to provide full clinical details. Seventy-five years later, Donaldson and Evans described patients with clinical features similar to those first described by Osler. The authors demonstrated a deficiency of $\mathrm{C} 1$ esterase inhibitor in the blood of these patients, although the extent of the deficiency was not able to be determined. Today, the biochemistry of the disease is better understood, but clinicians have low awareness of hereditary AE (HAE) and other types of non-allergic AE. Therefore, HAE is frequently undiagnosed. Approximately $50 \%$ of patients will be symptomatic by age 10[2]. However, accurate diagnosis may be delayed by decades[2]. For many, the disease results in multiple emergency department visits per year,[3] and for those patients with abdominal symptoms, one third may be subjected to inappropriate medical intervention due to misdiagnosis[4]. The fear of death from asphyxiation is an unfortunate but common part of life for many patients with HAE because of the risk of laryngeal swelling.

\footnotetext{
* Correspondence: eidelmf@ccf.org

1 Department of Allergy and Immunology, Medical Informatics, Cleveland Clinic Florida, 2950 Cleveland Clinic Blvd, Weston, FL 33331, USA Full list of author information is available at the end of the article
}

New medications are available for prophylaxis and acute treatment of patients with HAE. These new medications offer targeted actions that reduce the potential for long-term adverse effects, such as those experienced with long-term androgen exposure, and they have quick onset action, making them the best choice for acute treatment. Increased awareness of HAE symptoms, of available diagnostics, and of available treatments among clinicians will help reduce time to diagnosis and improve disease management. The following discussion will help clinicians identify HAE and choose among available therapies.

\section{Mechanism of disease}

HAE affects 1:10,000 to 1:50,000 people and is caused by mutations in the $\mathrm{C} 1$ inhibitor gene[5]. The $\mathrm{C} 1$ inhibitor gene is located on chromosome 11, and multiple mutations resulting in $\mathrm{C} 1$ inhibitor deficiency have been identified. Since C1 inhibitor has a broad inhibitory role, C1 inhibitor deficiency affects the regulation of multiple plasma cascade pathways, namely the contact, fibrinolytic, and complement pathways. $\mathrm{C} 1$ inhibitor binds irreversibly in these pathways. Therefore, new $\mathrm{C} 1$ inhibitor molecules are needed to maintain homeostasis once the substrate is bound. However, people with HAE have $\mathrm{C} 1$ inhibitor levels $<50 \%$ of normal, and they cannot produce $\mathrm{C} 1$ inhibitor fast enough to offset consumption in 
activated pathways[6]. Massive bradykinin release via the contact pathway is thought to be the primary cause of symptoms in both $\mathrm{HAE}$ and acquired $\mathrm{AE}[7,8]$. Therefore, the contact pathway has been a target of therapeutic investigation because $\mathrm{C} 1$ inhibitor blocks the activity of factor XII and kallikrein in this pathway[6]. Since plasma kallikrein releases bradykinin from high-molecularweight kininogen, its inhibition has also been a target of investigation[6].

Approximately $85 \%$ of HAE cases are type 1, a deficiency in the amount of $\mathrm{C} 1$ inhibitor produced. Nearly all other cases are type $2 \mathrm{HAE}$, which is characterized by the expression of dysfunctional $\mathrm{C} 1$ inhibitor. Inherited $\mathrm{C} 1$ inhibitor deficiency with normal $\mathrm{C} 1$ inhibitor activity (formerly HAE type 3 ) is a very rare disorder seen primarily in women and may be caused by increased activity of factor XII within the contact pathway, leading to increased bradykinin and angioedema[2,9]. Although HAE is primarily an autosomal dominant inherited disease, it appears de novo in approximately $25 \%$ of cases due to spontaneous mutations.

\section{Presentation and differential diagnosis}

Although no clear bias for sex or race has been observed for HAE, it appears to affect women more severely due to fluctuating estrogen levels[10]. Evidence for estrogen sensitivity comes from reports of worsening symptoms while using estrogen-containing oral contraceptives, but not progesterone-only oral contraceptives[2,11].

Trauma and stress are the most commonly reported triggers for HAE attacks[12]. In many cases however, there is no obvious trigger. Swelling episodes due to HAE typically worsen over one to two days and then resolve within an additional two days. More severe attacks may involve 5 days of unremitting symptoms[13]. Any individual part of the body or multiple sites may be affected[8]. Patients may experience prodromal symptoms that include tingling or burning in the area of an imminent attack [9]. Erythema marginatum, a serpiginous, non-pruritic rash may appear on the trunk and appendages as part of the prodrome in one-third of patients[9]. Inflammation and allergy are not implicated in HAE, and uritcaria is noteably absent during attacks[14].

More than $90 \%$ of patients will experience abdominal HAE attacks[12]. In most patients, the abdomen will be protuberant and tender[10]. Bowel sounds will vary between inactive and hyperactive, and guarding and rebound tenderness may be present[10]. The pain associated with abdominal angioedema may have a severe acute onset or recur as chronic abdominal pain of moderate severity[6]. Painful abdominal cramps are rated as severe to excruciating in $87 \%$ of patients[15]. In addition, $78 \%$ of patients report vomiting, and $65 \%$ report diarrhea with abdominal pain[15]. Constipation and intestinal obstruction may also occur[6,12].

Abdominal pain may occur for many years in the absence of cutaneous symptoms, but this is a rare occurrence[16]. HAE abdominal symptoms can be mistaken for other causes of abdominal pain, such as acute appendicitis[5]. Attacks are frequently accompanied by prodromal symptoms, including nonspecific complaints of irritability, aggressiveness, fatigue, or hunger[15]. Substantial fluid accumulation in the intestinal wall and lumen and in the peritoneal cavity will cause intestinal wall swelling and ascites. In rare cases, hypovolemic shock may occur due to the volume of fluid migration[16]. Patients with abdominal HAE symptoms may require narcotic analgesics for pain relief, and those at risk for hypovolemic shock will require aggressive rehydration.

Facial attacks will affect approximately half of all patients with HAE[6]. Facial attacks may involve severe swelling, and they carry significant risk of asphyxiation from extension to the larynx[17]. In the event of laryngeal involvement, intubation or tracheotomy may be required to prevent asphyxiation[12].

More than 95\% of patients with HAE will experience extremity attacks[12]. Urogenital attacks are common as well[8]. Both types of attacks can be triggered by normal activity and may cause enough discomfort to require treatment.

In the absence of treatment, a patient with HAE may experience weekly attacks[9]. Others may have symptomfree periods of a year or more[18]. Although causes include physical trauma, surgical/medical/dental procedures, repetitive daily activities, prolonged standing, infection, emotional stress, and certain medications, often the cause for an attack cannot be identified $[2,8,10,12]$.

During an attack, the clinical symptoms of HAE will include non-pitted, non-pruritic subcutaneous or submucosal edema, with a possible non-pruritic serpentine erythematous rash, and may include multiple sites of swelling[9]. Patients may also experience burning and pain at the affected site. The extent of $\mathrm{C} 1$ inhibitor deficiency is not related to symptom severity or to the bodily location of an attack[19]. A diagnostic algorithm is provided to help rule out causative agents and diseases and to guide laboratory study interpretation (Figure 1).

A thorough patient history and laboratory evaluation will aid in the differential diagnosis. In $75 \%$ of cases, a thorough patient history will reveal recurrent swelling episodes without urticaria, a family history of these episodes, symptom emergence around age 10, and more severe symptoms starting at puberty[9,10]. Laboratory markers that will help clinicians distinguish among AEs appear in Table 1. C4 complement levels are typically low 


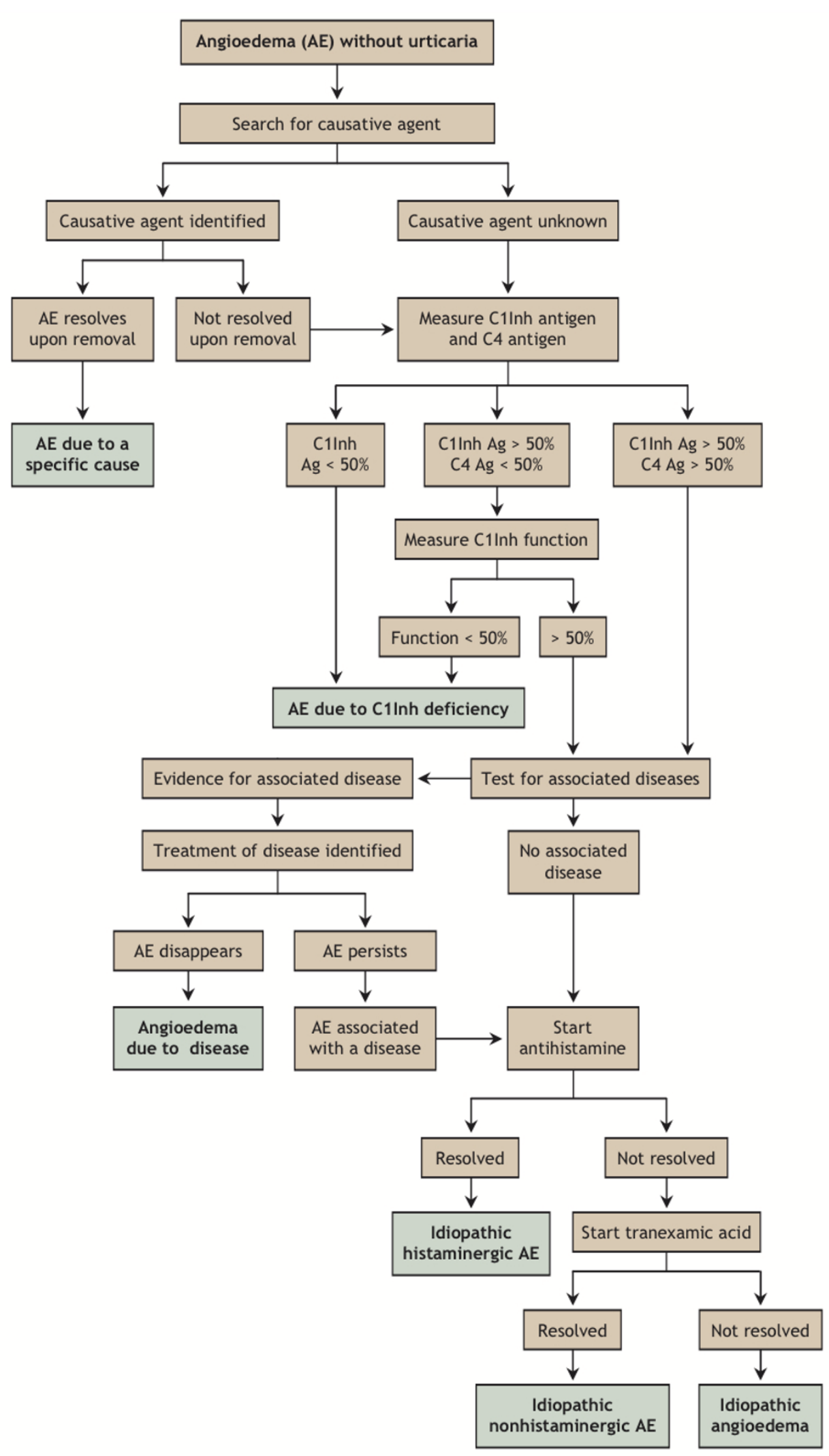

Figure 1 HAE differential diagnostic algorithm. C4 complement protein levels can be used as a screening test for HAE. Low C1 inhibitor levels support an HAE diagnosis in the absence of a family history since $25 \%$ of HAE cases are the result of spontaneous mutations in individuals. Reproduced with permission from Zingale et al.[35] 
Table 1: C1 inhibitor levels and complement protein concentrations in angioedemas.

\begin{tabular}{|c|c|c|c|c|c|}
\hline Angioedema Type & C1 inhibitor & $\begin{array}{c}\text { Functional C1 } \\
\text { inhibitor }\end{array}$ & C4 & C3 & C1q \\
\hline HAE type 1 & $<30 \%$ & $<30 \%$ & Low & Normal & Normal \\
\hline HAE type 2 & Normal/High & $<30 \%$ & Low & Normal & Normal \\
\hline $\begin{array}{l}\text { Inherited angioedema with normal C1 } \\
\text { inhibitor }\end{array}$ & Normal & Normal & Normal & Normal & Normal \\
\hline Acquired & Low & Low & $<30 \%$ & Normal/Low & Normal/Low \\
\hline $\begin{array}{l}\text { Angiotensin converting enzyme } \\
\text { inhibitor induced }\end{array}$ & Normal & Normal & Normal & Normal & Normal \\
\hline Idiopathic & Normal & Normal & Normal & Normal & Normal \\
\hline
\end{tabular}

in HAE, whereas $\mathrm{C} 1 \mathrm{q}$ and $\mathrm{C} 3$ are typically normal[9]. Normal C4 levels during periods of wellness does not preclude the HAE diagnosis, and repeat values should be measured during an acute attack when they are depressed. Testing for $\mathrm{C} 1$ inhibitor antigenic and functional levels provides for a definitive diagnosis and helps distinguish between HAE types 1 and 2[9].

To further complicate the diagnosis, HAE presentation may appear to be indistinguishable from idiopathic, acquired, allergic, or medication-induced AE if the family history of recurrent swelling is either unknown or absent - as in the case of spontaneous mutations. In addition, laboratory studies may prove inconclusive[20]. For example, a low/normal C1q level would not help the clinician distinguish between HAE and acquired angioedema. Therefore, clinicians may need to include genetic testing to make a definitive diagnosis. These tests are typically conducted in research laboratories since commercial laboratories do not yet offer the tests. It is important to note that not all mutations confer $\mathrm{C} 1 \mathrm{INH}$ deficiency. Clinicians can refer to the online database hae.biomembrane.hu as the most up-to-date source of documented mutations for comparison with results for their patients[21].

Idiopathic $\mathrm{AE}$ is the most common type of $\mathrm{AE}$, affecting one in five people[22]. Idiopathic $\mathrm{AE}$ is the presence of $\geq$ 3 swelling episodes in six months to one year despite treatment trials[22]. Urticaria and pruritis will be present in half of cases[22]. Acquired AE is usually caused by a lymphoproliferative disorder or other autoimmune, infectious, or neoplastic disease[6]. Acquired AE has symptoms that closely resemble HAE. However, these symptoms do not emerge until middle life, helping distinguish acquired AE from HAE[23]. Caution should be exercised when interpreting laboratory studies for $\mathrm{C} 1 \mathrm{q}$ since these levels may be normal in $25 \%$ of patients with acquired angioedema. A normal C1q result does not preclude a diagnosis of acquired angioedema[24,25].

ACE inhibitor use is the second most common cause of $\mathrm{AE}$ and may affect up to $6 \%$ of people taking these medications[26]. People of African descent are approximately 5 times more likely to experience this adverse event than people of European descent[26]. It typically presents in the first month of treatment, but may lie dormant for months or years[26]. The lips, tongue, and face are commonly affected sites, but the gastrointestinal tract may be involved[26]. ACE inhibitor-induced AE has a symptom pattern that is similar to HAE. This adverse event emerges when bradykinin degradation is slowed due to ACE inhibition[26]. The potential for increased availability of bradykinin makes this medication inappropriate for patients with HAE. Discontinuation remains the only treatment for ACE inhibitor-induced swelling.

In allergic $\mathrm{AE}$, histamine is released via IgE-mediated mast cell degranulation in response to environmental allergens. In some patients, degranulation results from medication or contrast medium exposure. Autoantibody action involving IgE receptors on mast cells or basophils is also implicated in allergic AE.

\section{Available therapies}

Available therapies are summarized in Table 2.

\section{Acute Treatment}

Two acute treatments have recently become available in the United States. These medications provide an advance in available acute treatments, particularly because they are quick acting and directed at targets implicated in the pathophysiology of HAE. Although $\mathrm{C} 1 \mathrm{INH}$ has been used for 30 years in Europe and is currently marketed 
under the name Berinert $\mathrm{P}^{\circ}$, this plasma-derived $\mathrm{C} 1$ esterase inhibitor (human) was recently approved in the United States for the treatment of acute abdominal or facial HAE attacks in adults and adolescents. The medication is marketed under the name Berinert in the United States[27]. In a randomized, double-blind, placebo-controlled study that enrolled 125 adults and adolescents with HAE, patients were randomized to $\mathrm{C} 1$ inhibitor 10 units $/ \mathrm{kg}, \mathrm{C} 1$ inhibitor 20 units $/ \mathrm{kg}$, or placebo intravenous infusion[28]. Patients who received the 20 units/ $\mathrm{kg}$ dose during an acute abdominal or facial HAE attack reported significantly shorter time to onset of relief compared with those receiving 10 units $/ \mathrm{kg}$ or those receiving placebo. Berinert is supplied in 500 unit vials and administered intravenously at a dosage of 20 units per $\mathrm{kg}$ of body weight. The most common adverse reactions included subsequent HAE attack, abdominal pain, diarrhea, headache, muscle spasms, nausea, pain, and vomiting.

The kallikrein inhibitor, KALBITOR ${ }^{\circ}$, was also recently approved in the United States for the treatment of acute HAE attacks in patients 16 years and older[29]. Kallikrein inhibitor has not been approved for use by the European Medicines Agency. KALBITOR ${ }^{\circ}$ was studied in two double-blind, randomized, clinical trials that enrolled 143 individuals. In these trials, patients who were having an HAE attack at any anatomic location and who were experiencing at least one moderate to severe symptom were randomized to either $30 \mathrm{mg}$ subcutaneous KALBITOR or placebo. Patients who received active medication reported statistically significant symptom improvement on a point-in-time symptom severity measure and a symptom response to treatment measure. More patients who received placebo required intervention for unresolved symptoms ( $50 \%$ vs. $33 \%$ of patients). KALBITOR is supplied in $10 \mathrm{mg}$ vials. The approved $30 \mathrm{mg}$ dosage is achieved via three subcutaneous injections, each containing $10 \mathrm{mg}$ of the medication. Common adverse events (occurring in $\geq 3 \%$ of patients and higher than placebo) in these trials included headache, nausea, diarrhea, pyrexia, injection site reactions, and nasopharyngitis. Adverse event rates were higher when patients who received intravenous infusion of KALBITOR ${ }^{\circ}$ were included in the analysis. KALBITOR ${ }^{\circ}$ carries the risk of anaphylaxis. A black box warning is included in the prescribing information.

Firazyr, icatibant (bradykinin $\beta_{2}$-receptor inhibitor), is approved in Europe for acute treatment. Icatibant has been studied in two clinical trials[21,30]. In the randomized, double-blind, placebo-controlled FAST-1 trial, no treatment difference was observed between subcutaneous icatibant $30 \mathrm{mg}$ and placebo in median time to symptom relief in adults with moderate to severe abdominal or cutaneous symptoms, although secondary endpoints showed benefit from icatibant administration. In the comparator-controlled, FAST-2 trial, subcutaneous icatibant $30 \mathrm{mg}$ was shown to reduce time to onset of symptom relief compared with tranexamic acid in adults with abdominal or cutaneous symptoms. Subanalyses of these trials suggest that icatibant may be as effective for laryngeal swelling as for abdominal and cutaneous symptoms, with a time to first symptom improvement of $\leq 1$ hour. Icatibant is supplied in a $30 \mathrm{mg}$ dose and is administered

Table 2: Therapies for various angioedemas .

\begin{tabular}{|c|c|c|}
\hline Angioedema type & Therapies* & \\
\hline $\begin{array}{l}\text { HAE type } 1 \\
\text { HAE type } 2 \\
\text { Inherited angioedema with normal C1 } \\
\text { inhibitor }\end{array}$ & $\begin{array}{l}\text { Acute treatment } \\
C 1 \text { inhibitor } \\
\text { Kallikrein inhibitor } \\
\text { Bradykinin } \beta_{2} \text {-receptor inhibitor }\end{array}$ & $\begin{array}{l}\text { Prophylaxis } \\
\text { C1 inhibitor } \\
\text { Danazol } \\
\text { Antifibrinolytics are used in clinical } \\
\text { practice. } \\
\text { There are no approved therapies for } \\
\text { medical/dental procedure prophylaxis. }\end{array}$ \\
\hline Acquired & $\begin{array}{l}\text { Acute treatment } \\
\text { C1 inhibitor is the treatment of choice for } \\
\text { laryngeal attacks. Doses greater than } 1000 \\
\text { units may be required. }\end{array}$ & $\begin{array}{l}\text { Prophylaxis } \\
\text { Treatment of underlying disease. } \\
\text { Antifibrinolytics are the first choice for } \\
\text { long-term therapy, followed by } \\
\text { attenuated androdgens. }\end{array}$ \\
\hline $\begin{array}{l}\text { Angiotensin converting enzyme } \\
\text { inhibitor induced }\end{array}$ & ACE inhibitor discontinuation. & \\
\hline Idiopathic & Antihistamines followed by glucocorticoids. & \\
\hline
\end{tabular}

*See text for United States vs. European approvals. 
subcutaneously. Common adverse events include mild injection-site reactions, abdominal pain, abnormal liver function tests, asthenia, dizziness, headache, nasal congestion, nausea, rash, and increased blood creatinine phosphokinase.

Rhucin, recombinant $\mathrm{C} 1$ inhibitor, is currently under review by the European Medicines Agency for the acute treatment of HAE attacks.

\section{Prophylaxis}

Routine prophylaxis has been shown to reduce the frequency and severity of HAE attacks. Danazol and C1 inhibitor are the only medications approved in the United States for prophylaxis. In Europe, attenuated androgens, antifibrinolytics, and $\mathrm{C} 1 \mathrm{INH}$ are used for prophylaxis. Although guidelines suggest that antifibrinolytics may be the least effective therapy[5]. The attenuated androgens, such as danazol, increase $\mathrm{C} 1$ inhibitor via the liver and carry the risk of long-term side effects[31]. An 84\% reduction in the mean number of HAE attacks was associated with danazol prophylaxis in a retrospective study of 118 patients[32]. Nearly one-quarter of patients reported no HAE symptoms while on danazol therapy. Other patients continued to have attacks at a reduced frequency. Danazol is supplied in $200 \mathrm{mg}, 100 \mathrm{mg}$, and 50 $\mathrm{mg}$ capsules and indicated for use in adults[33]. The 200 $\mathrm{mg}$ starting dose may be reduced to $100 \mathrm{mg}$ in patients who do not experience significant breakthrough symptoms[33]. In clinical practice, danazol may be initially dosed as high as $600 \mathrm{mg} /$ day and then titrated down to the lowest effective dose[9]. Adverse events were reported by nearly $80 \%$ of patients on danazol therapy and included weight gain, menstrual irregularities, female virilization, acne, headache, depression, and myalgia. Infrequent but serious cardiovascular and other adverse events were also reported.

The $\mathrm{C} 1$ inhibitor $\mathrm{CINRYZE}^{\mathrm{ma}}$ (C1 esterase inhibitor [human]) was recently approved in the United States for routine prophylaxis in adults and adolescents. In a randomized, double-blind, placebo-controlled, cross-over study, patients on active treatment experienced half as many HAE attacks as patients who received placebo[34]. Patients who experienced attacks while on $\mathrm{C} 1$ inhibitor therapy reported less severe and shorter attacks compared with those reported by patients on placebo. The study enrolled 24 patients with a history of $\geq 2 \mathrm{HAE}$ attacks per month. Patients were randomized to either treatment arm: 1) 12 weeks of $\mathrm{C} 1$ inhibitor therapy, then 12 weeks of placebo or 2) 12 weeks of placebo, then 12 weeks of $\mathrm{C} 1$ inhibitor therapy. Twenty-two patients crossed over and received at least one dose of each study drug and completed the entire study. CINRYZE ${ }^{\mathrm{mm}}$ is administered intravenously every 3 to 4 days at a dose of 1000 units[34]. Upper respiratory infection, sinusitis, rash, and headache were the most commonly reported adverse reactions [34].

Although there are no approved treatments for medical or dental procedure prophylaxis, consensus guidelines recommend administration of $\mathrm{C} 1$ inhibitor one hour prior to procedures, with additional doses available at the time of the procedure, and as necessary thereafter[5]. The guidelines recommend high-dose danazol and fresh frozen plasma as second-line therapy[9].

\section{Summary}

Advances in treatment for HAE have recently come to the market. These therapies have reduced potential for the long-term effects associated with attenuated androgen therapy and the adverse events associated with antifibrinolytics, both of which have been mainstays of treatment in the past. The newly available $\mathrm{C} 1$ inhibitor, kallikrein inhibitor, and bradykinin $\beta_{2}$-receptor inhibitor work directly to reduce the massive bradykinin release in the contact plasma cascade that is thought to be the primary pathological mechanism in HAE. Appropriate prophylactic and acute use of these medications will help reduce patient risk for disability and death. Increased awareness of this disease and efficient steps in its differential diagnosis are essential to improving patient outcomes.

\section{Competing interests}

Dr Eidelman has received clinical research funding from CSL Behring and Lev Pharmaceuticals and has received honoraria from Lev Pharmaceuticals, ViroPharma Incorporated, and CSL Behring.

\section{Authors' contributions}

FJE contributed to the initial concept and design of the manuscript, provided critical review of the medical concepts and data presented, and approved the final version.

\section{Acknowledgements}

Editorial support was provided by Clay Isbell and Innovated Strategic Communications LLC and was funded by ViroPharma Incorporated.

\section{Author Details}

Department of Allergy and Immunology, Medical Informatics, Cleveland Clinic Florida, 2950 Cleveland Clinic Blvd, Weston, FL 33331, USA

Received: 5 February 2010 Accepted: 14 May 2010

Published: 14 May 2010

References

1. Osler W: Hereditary angio-neurotic oedema. Am J Med Sci 1888 95:362-367.

2. Bork K, Barnstedt SE, Koch P, Traupe H: Hereditary angioedema with normal C1-inhibitor activity in women. Lancet 2000, 356:213-217.

3. Moore GP, Hurley WT, Pace SA: Hereditary angioedema. Ann Emerg Med 1988, 17:1082-1086.

4. Agostoni A, Cicardi M: Hereditary and acquired C1-inhibitor deficiency: biological and clinical characteristics in 235 patients. Medicine (Baltimore) 1992, 71:206-215

5. Bowen T, Cicardi M, Bork K, Zuraw B, Frank M, Ritchie B, Farkas H, Varga L, Zingale LC, Binkley K, et al:: Hereditary angiodema: a current state-ofthe-art review, VII: Canadian Hungarian 2007 International Consensus Algorithm for the Diagnosis, Therapy, and Management of Hereditary Angioedema. Ann Allergy Asthma Immunol 2008, 100(Suppl 2):30-40. 
6. Agostoni A, Aygoren-Pursun E, Binkley KE, Blanch A, Bork K, Bouillet L, Bucher C, Castaldo AJ, Cicardi M, Davis AE, et al:: Hereditary and acquired angioedema: problems and progress: proceedings of the third C1 esterase inhibitor deficiency workshop and beyond. J Allergy Clin Immunol 2004, 114(Suppl 3):51-131.

7. Cugno M, Zanichelli A, Foieni F, Caccia S, Cicardi M: C1-inhibitor deficiency and angioedema: molecular mechanisms and clinical progress. Trends Mol Med 2009, 15:69-78.

8. Nzeako UC, Frigas E, Tremaine WJ: Hereditary angioedema: a broad review for clinicians. Arch Intern Med 2001, 161:2417-2429.

9. Zuraw BL: Clinical practice. Hereditary angioedema. N Engl J Med 2008 359:1027-1036.

10. Frank MM: Hereditary angioedema: the clinical syndrome and its management in the United States. Immunol Allergy Clin North Am 2006, 26:653-668.

11. Bouillet $L$, Longhurst $H$, Boccon-Gibod I, Bork K, Bucher C, Bygum A, Caballero T, Drouet C, Farkas H, Massot C, et al:: Disease expression in women with hereditary angioedema. Am J Obstet Gynecol 2008, 199:e481-484

12. Frank MM, Gelfand JA, Atkinson JP: Hereditary angioedema: the clinical syndrome and its management. Ann Intern Med 1976, 84:580-593.

13. Zuraw BL: Hereditary angiodema: a current state-of-the-art review, IV: short- and long-term treatment of hereditary angioedema: out with the old and in with the new? Ann Allergy Asthma Immunol 2008, 100(Suppl 2):13-18

14. Davis AE: Mechanism of angioedema in first complement component inhibitor deficiency. Immunol Allergy Clin North Am 2006, 26:633-651.

15. Bork K, Staubach P, Eckardt AJ, Hardt J: Symptoms, course, and complications of abdominal attacks in hereditary angioedema due to C1 inhibitor deficiency. Am J Gastroenterol 2006, 101:619-627.

16. De Backer Al, De Schepper AM, Vandevenne JE, Schoeters P, Michielsen $P$, Stevens WJ: CT of angioedema of the small bowel. AJR Am J Roentgenol 2001, 176:649-652.

17. Bork K, Barnstedt SE: Laryngeal edema and death from asphyxiation after tooth extraction in four patients with hereditary angioedema. J Am Dent Assoc 2003, 134:1088-1094.

18. Bork K, Meng G, Staubach P, Hardt J: Hereditary angioedema: new findings concerning symptoms, affected organs, and course. Am J Med 2006, 119:267-274.

19. Gompels MM, Lock RJ, Abinun M, Bethune CA, Davies G, Grattan C, Fay AC, Longhurst HJ, Morrison L, Price A, et al: C1 inhibitor deficiency: consensus document. Clin Exp Immunol 2005, 139:379-394.

20. Weiler CR, van Dellen RG: Genetic test indications and interpretations in patients with hereditary angioedema. Mayo Clin Proc 2006, 81:958-972.

21. CHMP assessment report for Firazyr [http://www.ema.europa.eu/ humandocs/PDFs/EPAR/firazyr/H-899-en6.pdf

22. Frigas E, Park M: Idiopathic recurrent angioedema. Immunol Allergy Clin North Am 2006, 26:739-751.

23. Grigoriadou S, Longhurst HJ: Clinical Immunology Review Series: An approach to the patient with angio-oedema. Clin Exp Immunol 2009, 155:367-377.

24. Kalmar L, Hegedus T, Farkas H, Nagy M, Tordai A: HAEdb: a novel interactive, locus-specific mutation database for the $\mathrm{C} 1$ inhibitor gene. Hum Mutat 2005, 25:1-5.

25. Zingale LC, Castelli R, Zanichelli A, Cicardi M: Acquired deficiency of the inhibitor of the first complement component: presentation, diagnosis, course, and conventional management. Immunol Allergy Clin North Am 2006, 26:669-690.

26. Byrd JB, Adam A, Brown NJ: Angiotensin-converting enzyme inhibitorassociated angioedema. Immunol Allergy Clin North Am 2006, 26:725-737

27. Berinert [package insert]. Kankakee, IL: CSL Behring; 2009

28. Craig TJ, Levy RJ, Wasserman RL, Bewtra AK, Hurewitz D, Obtulowicz K, Reshef A, Ritchie B, Moldovan D, Shirov T, et al.: Efficacy of human C1 esterase inhibitor concentrate compared with placebo in acute hereditary angioedema attacks. J Allergy Clin Immunol 2009, 124:801-808.

29. KALBITOR [package insert]. Cambridge, MA: Dyax; 2009

30. Deeks ED: Icatibant. Drugs 70:73-81.

31. Epstein TG, Bernstein JA: Current and emerging management options for hereditary angioedema in the US. Drugs 2008, 68:2561-2573.
32. Bork K, Bygum A, Hardt J: Benefits and risks of danazol in hereditary angioedema: a long-term survey of 118 patients. Ann Allergy Asthma Immunol 2008, 100:153-161.

33. Danazol [package insert]. Philadelphia, PA: Lannett; 2007.

34. CINRYZE [package insert]. New York, NY: Lev Pharmaceuticals; 2008.

35. Zingale LC, Beltrami L, Zanichelli A, Maggioni L, Pappalardo E, Cicardi B, Cicardi M: Angioedema without urticaria: a large clinical survey. CMAJ 2006, 175:1065-1070.

\section{Pre-publication history}

The pre-publication history for this paper can be accessed here: http://www.biomedcentral.com/1471-2326/10/3/prepub

doi: 10.1186/1471-2326-10-3

Cite this article as: Eidelman, Hereditary angioedema: New therapeutic options for a potentially deadly disorder BMC Blood Disorders 2010, 10:3

\section{Submit your next manuscript to BioMed Central and take full advantage of:}

- Convenient online submission

- Thorough peer review

- No space constraints or color figure charges

- Immediate publication on acceptance

- Inclusion in PubMed, CAS, Scopus and Google Scholar

- Research which is freely available for redistribution

Submit your manuscript at www.biomedcentral.com/submit
C Biomed Central 